\title{
SENSORY PROPERTIES AND PHYSICO-CHEMICAL ANALYZES OF PASTEURIZED MILK
}

\author{
Jetmir Prekalla ${ }^{1}$, Nexhdet Shala ${ }^{2 *}$, Arsim Elshani ${ }^{3}$ \\ 1,2*3, Peja University “Haxhi Zeka”, Faculty of Agro-business, Peja 30000, Kosovo; \\ ${ }^{1}$ Kosovo Institute of Agriculture Peja Str. "Adem Jashari”, 30000, Kosovo; \\ *Corresponding author, Nexhdet Shala, e-mail: nexhdet.shala@unhz.eu;
}

Received June 2019; Accepted July 2019; Published August 2019;

DOI: https://doi.org/10.31407/ijees9315

\begin{abstract}
Pasteurized milk products, widely used in dietary diets, are highly popular products in the dairy industry. Safety and control of these products is part of food safety and includes technological processes as well as additional substances approved by the state standard. Additives in pasteurized milk products are used to perform a variety of functions, both to improve their taste, texture and longevity. Notwithstanding this, consumers should not be jeopardized in their health when consuming these foods and the use of these pasteurized milk products is regulated by legislation in different countries and between EU countries, many additives are listed in Directives 94/35 / EC, 94/36 / EC2 and 95/2 / EC3 on dyestuffs, sweeteners, antimicrobial substances, antioxidants, and other additives applied by EU countries. By standard analytical methods they were evaluated for a period of several days from pasteurized milk products obtained from the network of supermarkets in several cities of Kosovo and produced by the most popular Kosovar firms in milk processing. The samples were selected taking into account the storage time and temperature and were analyzed in relation to physico-chemical indicators and the amount of additional substances used in dairy products.
\end{abstract}

Keywords: antimicrobial substances, antioxidants, pasteurized milk, sweeteners. 